\title{
Can we select health professionals who provide safer care
}

\author{
J Firth-Cozens, H Cording, R Ginsburg
}

Qual Saf Health Care 2003;12(Suppl 1):i16-i20

In order to improve patient safety, health services are looking to other industries' experiences and as a result are adopting a systems approach to learning from error, rather than simply focusing the blame on the individual. However, in health care the individual will remain an important contributor to safety and this paper looks at other literatures besides health to consider a number of individual characteristics and the role they might play in terms of work practices that affect patient safety. It considers the effects of a variety of personality profiles including sensation seeking, Type $A$, and those with high self esteem; looks at our ability to select for psychological wellbeing; and discusses the ways that psychometrics have been used in medicine to predict performance. It concludes that although rarely used, psychometrics has been shown to be useful in predicting some aspects of performance in medicine and suggests that this is an area well worth further study for the benefit of patient care.

Nevertheless, we are a long way away from being able to select safer staff and should instead be developing this knowledge to enable us to recognise and address potential difficulties.

See end of article for authors' affiliations

Correspondence to:

Correspondence to:
Professor J Firth-Cozens, The London Deanery, 20 Guilford Street, London WCIN 1DZ, ÚK; jfirth-cozens@ ondondeanery.ac.uk
$\mathrm{T}$ he emphasis on patient safety has, over the past few years, shifted from blaming the individual to focusing upon the system that led or might lead to accidents. ${ }^{1}$ This has proved a very useful approach in other industries such as aviation, ${ }^{2}$ and within health care this should bring about change too, by helping us understand both the less frequent but serious errors and those smaller slips that occur again and again. The previous focus, upon the individual staff member, has isolated responsibility in ways that have meant that organisations need not learn from error. ${ }^{3}$ Nevertheless, the blame free culture sometimes implied by a shift in responsibility totally away from the individual would be inappropriate in health care, where the relationship and actions that occur between the patient and the staff member will inevitably have some effect upon outcome. We know from banks, for example, that dissatisfied staff lead to dissatisfied customers ${ }^{4}$; and within health care too there are studies that show that the quality of patient care, such as their general adherence to treatment $^{5}$ and no show rates, ${ }^{6}$ are related to physician and patient satisfaction. These areas of literature show that the one to one staffpatient relationship matters.

Some actions of the individual that lead to poor care are going to be due to a lack of knowledge or competence, both of which may be improved when they are recognised. However, others are likely to be more dispositional or attitudinal, leading to poor interactions with patients or other staff, or to a greater likelihood of providing care that is risky.

In this case, selecting staff who, because of their particular personality or psychological make up, are more mindful of safety, might be seen as a way of working differently to the ultimate benefit of patient care. To judge whether this is possible to achieve, this paper reviews a wide range of literature where the relationship between individual factors and risk have been studied, and asks whether we canand whether we should-be selecting for safety.

\section{PERSONALITY AND RISK}

There is much literature now on an individual's risk propensity in terms of personality, mainly focusing on mountaineers, criminals, gamblers, and those who take part in unsafe sex, but also involving risky workplaces, such as Antarctica. ${ }^{7}$ In these studies risk taking has naturally been seen as a bad thing, leading to poor outcomes. However, throughout this discussion we must remember that how risk is viewed will always depend on the contex; for example, a metaanalysis $^{8}$ has shown entrepreneurs to have an appropriately higher risk taking propensity than managers. Similarly, where the relationship between personality and safe performance has been addressed within health care, it has not necessarily been seen negatively; one study examines nurses who become managers and who may not have sufficient risk propensity to deliver services more intensely, faster, and at lower cost. ${ }^{9}$ In some cases, a propensity to take extra risks may be a necessity of the job, and a characteristic that some would argue is also a requirement within various fields of medicine, in particular surgery.

Despite this viewpoint, most studies focus on the negative aspects of risk propensity, and it is this aspect of the literature that has implications for patient safety.

\section{Risk perception}

Risk perception is an important aspect of risk creation-if a doctor or nurse is able to see risk, then it is likely that he or she is more likely to do something to avoid it. This underlies the practice of one surgeon in using his early morning swim as a time to think about his cases that day and of all the possible things that he could anticipate going wrong and a recent paper on the links between certain behaviours and patient outcomes suggests this type of anticipation is important. ${ }^{10}$

However, the association between being able to perceive risk and changing one's behaviour 
accordingly is not so clear cut $^{7}$ because some people might actually favour the thrill that comes from the danger they see, or they may believe, with unrealistic faith, in the protection and infallibility of their safety systems. Certainly people's perception of risk increases once they have sustained a major incident. For example, after the destruction of some towns by Hurricane Hugo, huge precautions were put in place by those who had been hit to prevent future damage on that scale. However, the towns nearby, which the hurricane by chance barely missed, were much less likely to make changes, ${ }^{11}$ their risk perception remained low. There is evidence that strongly held views on risk levels are actually quite resistant to change even if objective data on hazards, such as reports of death or disability, are given. ${ }^{12}$ This suggests either some form of magical thinking ("it can't happen to me") of the type we saw in towns that the hurricane missed, or strong personality factors are at play.

\section{Sensation seeking}

If you can see risks but actually are still attracted to them, then your behaviour falls within the area of the risky personality. Someone with this psychological make up may simply choose an area of health care where risk is higher and be satisfied by that, but it is also possible that they might choose procedures that are more dangerous, or generally deliver less safe care.

There is growing evidence across decades and across continents that some aspects of personality, in particular that termed "sensation seeking", are related to a variety of dangerous behaviours, such as gambling, drug and alcohol misuse, speeding, extreme sports, and violence. ${ }^{13}$ The concept of sensation seeking includes factors of disinhibition, thrill and adventure seeking, impulsivity, boredom susceptibility, sociability, and aggression, depending upon the measure; a study of adolescents found that risk seeking predicted delinquent behaviours of alcohol misuse and risky driving. ${ }^{14}$ Moreover, high sensation seekers tend to perceive risk as lower than low sensation seekers and anticipate less anxiety when they are in the situation. ${ }^{15}$ Although sensation seeking has been shown to be linked to biochemical processes, ${ }^{16}$ cognitive processes also appear to have a role in influencing decisions ${ }^{17}$ and this is likely to be a more useful target for change. There is evidence too that sensation seeking may be used to compensate for anhedonia; a study of skydivers showed higher sensation seeking alongside more anhedonia and blunted affect than controls. ${ }^{18}$

Although the types of activities studied in research on sensation seeking may seem a long way away from any behaviours that might compromise safety in health care, this is a link that makes sense intuitively but one that has almost never been considered. However, in a study that used the Zuckerman sensation seeking scales ${ }^{19}$ as one of several potential predictors of risky behaviour in nurses, logistic regressions showed that higher disinhibition predicted having at least one occupational exposure to blood. Also, disinhibition, alongside a greater susceptibility to boredom, having less nursing experience, and having a permanent position, predicted having a larger number of these exposures-a mixture of individual characteristics, and traditional job related factors. ${ }^{20}$ If we are looking for characteristics that may make a health worker less safe, then sensation seeking seems to be one worthy of further investigation.

\section{Type A personality}

Type A personality, found in those people who are more aggressive, competitive, and impatient, was originally recognised as a predictor of increased risk of coronary heart disease. However, differences between Type A and Type B individuals also show differences in various vocational activities and performances, ${ }^{21}$ and Type A personality has been found to be related to having more traffic accidents, greater frequency of breaking traffic laws, higher impatience when driving, more aggression on the road, and more risky driving behaviours. ${ }^{22}$ The forceful, confident Type A is highly rewarded in the modern world, presumably also within medicine and nursing, and, therefore, another area for future research would be to see the extent to which the personality safety records of Type A people match those of Type B.

\section{Unskilled and unaware}

There is a growing area of individual differences that may also have implications for health professionals, particularly those working in some isolation where feedback may be less. A series of studies ${ }^{23}$ has shown that most of us overestimate our skills. However, people who are particularly unskilled in certain areas are actually more likely to overestimate their abilities. The authors see this as a deficit in metacognitive skill, or the capacity to distinguish accuracy from error. Although it sounds like a paradox, improving their skills actually increased this capacity and helped them recognise their limitations better. This area has been applied to medical students, ${ }^{24}$ where the study showed that individual self assessments are stable over time, regardless of performance, but that there is an overall fall in accuracy (in both accurate and inaccurate students) when they begin the more complex clinical work with patients. In these days of error reporting and learning from error, this may be important not only in terms of educational planning but also in the essential step of recognising that an error has been made at all.

\section{Confidence and self esteem}

Confidence is usually regarded as a good characteristic for medical practitioners, as it is for other professionals. Doctors need to be able to show confidence to increase the reassurance they might provide for patients, and a lack of confidence would be a worrying trait in a team member such as the anaesthetist or the surgeon. However, like other related characteristics such as self criticism and self esteem, it is likely that not only too little confidence, but also too much confidence can cause harm. For example, high self criticism is related to depression in doctors, while those with particularly low self criticism have more problems with colleagues and with patients. ${ }^{25}$ Similarly, while low self esteem is related to depression, high self esteem has frequently been linked to aggression. ${ }^{26}$ Theorists are now seeing this as a reflection not so much of high self esteem, but as an underlying insecurity that leads to more grandiose, narcissistic behaviours that, when threatened, can cause aggression. ${ }^{27}$ With the reported levels of bullying in health care being so high and potentially affecting teamwork and safety, the type of self image that gives rise to aggressive behaviours is again an aspect of the individual worth considering in terms of patient care.

\section{Attitudes and performance}

Although there is not always a direct relationship between attitudes and performance at the individual level, ${ }^{28}$ performance at the organisational level has been found to be related to staff attitudes. ${ }^{29}$ Having the right attitude towards the need for safe, thoughtful care is important and recognised within most high risk industries. For example, a number of aviation studies by Helmreich and his colleagues have shown the links between attitude and performance in terms of aircraft management and safety. Those pilots independently rated as outstanding or as extremely poor differed significantly in their previously measured attitudes to cockpit management. ${ }^{30}$ The items which most clearly distinguished them were:

- My decision making ability is as good in emergencies as in routine flying situations (superior ones disagreed) 
- Captains should encourage their first officers to question procedures during normal flight operations and in emergencies (superior ones agreed)

- Pilots should be aware of and sensitive to the personal problems of fellow crew members (superior ones agreed)

- There are no circumstances (except total incapacitation) where the first officer should assume command of the aircraft (superior ones disagreed).

The study concluded that pilots rated as extremely poor epitomised the stereotype of the "macho" pilot, one who "does not recognize personal limitations due to stress and emergencies, does not utilize the resources of fellow crewmembers, is less sensitive to problems and reactions of others, and tends to employ a consistent, authoritarian style of management" (ref 30; pl200).

They later showed that such attitudes could be changed with crew resource management training in all but a small group of pilots. ${ }^{31}$ However, in this group attitudes actually worsened over the course. They were the pilots who were low in both autocratic traits but also in expressive interpersonal characteristics, as well as being poor in performance. The authors called them the "no stuff", as opposed to the "right stuff" and the "wrong stuff" (those who were autocratic), both of which categories changed for the better. They concluded that this has the worrying implication that "the types of individuals who seem to need the training most may be less likely to be influenced in the desired manner" (ref 30;p.298).

These findings very much fit those that have implications for the effects of different leadership styles on safety and quality in health care. ${ }^{32}$ They stress the importance of getting senior nurses and doctors to appreciate their own limitations, as well as the importance of genuine interaction within the team in terms of safety. The fact that most people are to some extent changeable in this regard, stresses the value of good team leadership training within health care.

\section{PSYCHOLOGICAL HEALTH AND SAFETY}

There is a wide array of research to suggest that people who are stressed, depressed, or alcohol dependent, or even simply dissatisfied or exhausted, are less likely to provide the same standards of care than those who are not.. ${ }^{33}$ For example, those surgeons showing behaviours indicating high emotional resilience have better outcomes than others. ${ }^{10}$ There is evidence too that hospitals that have reputations for being good places to practise actually have lower staff burnout and better patient outcomes than those without such attractions. ${ }^{34}$ This suggests that the effects of stress in doctors on their patients may be a systems problem like any other, ${ }^{33}$ but also that it still needs to be recognised (as part of this system) that people who are suffering emotionally may be less safe and need support at these times. Life events, for example, have links to both psychological and physical health, and there is evidence that they influence the risk of injury in athletes, particularly if social support is $\operatorname{low}^{35}$ ). Moreover, some people-for example, doctors with high self criticismmay be more likely to be emotionally at risk than others. ${ }^{36}$

Chemical dependency in United States doctors has a lifetime prevalence of $10-15 \%,{ }^{37}$ and alcoholism is said to be particularly high in the medical profession. ${ }^{38}$ Unusually, women doctors have similar rates of alcoholism to those of men, ${ }^{39}$ and Flaherty and Richman ${ }^{40}$ report that female medical students are the only group whose drinking increases over their undergraduate years. In terms of alcohol misuse, there are very few longitudinal studies of the precursors; however, a United States study shows that, in terms of individual factors, having a technological orientation to medicine, as opposed to an interpersonal one, is predictive, ${ }^{41}$ while workplace abusive experiences in interaction with personal vulnerability (termed narcissism) best explains drinking outcomes in the longer term. Nevertheless, there remains little in this literature on psychological distress and dependency, which would allow us with any accuracy to select staff who are likely to be more resilient to the very real pressures of health care, and so to be safer.

\section{CONTEXT}

As shown in the search for long term predictors of psychological problems, work based variables often interact with individual differences to create the conditions that may lead to risk to patients. For example, the second generation of research on risky personality has been improved considerably by a search for interactions with moderating variablesaspects of the environment that might exacerbate or buffer against the risks created by the individual. ${ }^{42}$ For instance, the influence of sensation seeking on drinking is strongest in boring situations, whereas the influence of neuroticism on drinking is strongest in stressful situations. ${ }^{43}$ Sicard ${ }^{44}$ used a different measure of risk propensity, the evaluation of risks, on a group of pilots subjected to strenuous night flights with sleep deprivation. Unlike the control group, they increased in impulsiveness after the exercise, as well as being more clumsy and having lower mood. We know from numerous studies that cognitive ability and dexterity deteriorate with sleep loss, ${ }^{45}$ but these findings suggest that sleep loss may also increase risky behaviours, and this is likely to be even more of a problem in those with a risky personality. This too is an important area for future study.

Of course, some contexts may interact with personality badly in terms of satisfaction with career choice. For example, a doctor whose obsessionality and need for order is high may be particularly unhappy as an inner city general practitioner; while a young doctor who is depressed may find that becoming a psychiatrist makes his or her problems worse $^{36}$ and this can then affect patient care. For this reason career counselling early in the process seems as essential in medicine as it is in other occupations, particularly as it is difficult to change pathways.

Given that the research suggests there may well be individual psychological issues involved in the provision of quality care, the next section looks at how psychometrics has been used to date within medicine.

\section{PSYCHOMETRIC TESTING IN MEDICINE}

Within medicine a shift in the recruitment process has taken place. The old paradigm of unstructured short listing, interviewing, and referencing, frequently supported by "off the record" phone calls, has been replaced by criteria for short listing that become the basis for decision making. Interview panels favour scenarios that involve a safety component. ${ }^{46}$ Structured references requesting information on sample characteristics may then throw additional light on previous safety behaviour, although it may not be predictive.

Despite this progress in medical recruitment, the use of psychometrics as a selection tool has taken place only rarely within medicine, and often only to complement traditional selection procedures, primarily in anaesthetics or surgery. ${ }^{47} 48$ Nevertheless, where it has been used and linked to later performance, it has been remarkably successful. In a seminal paper, Hunter and Hunter ${ }^{49}$ demonstrated that psychological testing out ranked all other factors in predicting ultimate job performance, although these did not directly address safety matters. Also striking was the very low validity coefficient for interviewing, a feature that is common in research on selection. Conversely, Bobko et al ${ }^{50}$ demonstrated that the use of alternative predictors alone to predict job performance 
(in the absence of cognitive ability) lowered their potential for identifying likely poor performers.

A study by Ferguson et $a l^{51}$ on performance during undergraduate years suggests that references do not consistently predict performance, while analysis of the content of the free response personal statement is predictive of clinical aspects of training. Reference categories covered character and social skills, whereas personal statement categories covered motivation and hobbies. A-level grades predict pre-clinical performance only; but conscientiousness was the best predictor across the course as a whole. They concluded that inclusion of personal statements and evaluation of conscientiousness would aid selection.

Reeve et $a l^{47}$ also used personality testing (Cattell's 16 Personal Factor Questionnaire) and interviews on a cohort of 62 anaesthetists appointed to a training scheme, and followed them up for 3-8 years using academic, clinical, behavioural, and overall performance as criteria of outcome. The positive ends of the primary factors of dull/bright, unstable/stable, timid/socially bold, and casual/controlled predicted better performance. However, there was also evidence of a non linear relationship on some factorsdetached/warm hearted, expedient/conscientious, and relaxed/tense-indicating that scoring nearer to the middle of the scale was predictive of better performance. Interview ratings also had a significant, though smaller, relationship with outcomes, and the combination of the two methods accounted for $52 \%$ of the variance. This study has largely been supported by others from the US. ${ }^{52}$ Though the important factors do map quite closely onto the Big Five indicators of good leadership skills, ${ }^{32}$ these studies can only be said to show us the personality factors that are important for successful performance in anaesthesiology; not necessarily those for general practice or for other specialties, such as psychiatry or surgery.

In the Harvard Medical Practice Study, ${ }^{53} 48 \%$ of all adverse events related to surgical interventions, with $17 \%$ of these seen as negligent. Being able to select surgeons who are good at risk perception and risk avoidance seems important. However, the issues for surgeons are particularly complex when one considers that a willingness to take risks will so often be required. Hall et $a^{54}$ suggest that we should be training and assessing our young surgeons in higher order cognitive skills such as problem solving and the justification of actions, but selection for surgery according to such criteria has not taken place to our knowledge. Certainly we know that surgeons have different personalities to those in other specialties ${ }^{48}$ and this is true right from student days ${ }^{55}$; what we do not know is whether these personality differences have any bearing on performance, including the safety of their care. Work has been done on the attributes necessary for a good surgeon $^{5657}$ showing that spatial reasoning was the most important, along with verbal reasoning in terms of communication skills. In regard to personality, studies have used a variety of test $\mathrm{s}^{58-60}$ but clarity and agreement about the best outcome measures still needs to be decided, and should include a reliable assessment of safety from all its perspectives.

Being able to stand ambiguity is often said to be important in medicine, and a study by Merrill et $a^{l^{61}}$ showed that intolerance of ambiguity is related to over reliance on high technology, a negative view of psychological problems, and the Machiavellian attitude that the means justify the end, characteristics which may be thought to affect patient care. They also found that these students were more likely to favour surgery as a career.

Most studies of individual specialties or of those which compare one specialty with another ${ }^{48}$ do show that personalities and skills differ between them in quite dramatic ways

\section{Key messages}

- The individual health professional is an important contributor to patient safety.

- There is strong evidence from other domains that a risky personality exists and has an effect on behaviour.

- Despite almost no consideration of personality in health care, what exists supports this evidence.

- The individual characteristics most likely to affect safety are low risk perception, sensation seeking, Type A behaviour, high self esteem, psychological ill health, and attitudes concerning safety.

- Where psychometrics has been used in medicine for selection, this has been shown to have strong implications for later performance.

- Research in this area is needed in health care and should be used to enable recognition of potential difficulties rather than for selection.

that can be traced back to student days and so are not simply a reflection of the job..$^{55}$ Given the lack of systematic career counselling that takes place in medicine, this seems to be a process of natural selection occurring at specialisation and earlier. If this truly takes account of likes and dislikes, then it may mean that this process is positively geared towards safer clinicians, because satisfied doctors give higher quality care; ${ }^{6}$ however, chance clearly plays a large part in choice. $^{62}$

This review of studies shows that personality testing in medicine has begun slowly and is still in its infancy. In other areas of health care, apart from management, we have even less experience of its use.

\section{CONCLUSIONS}

Although rarely used, psychometrics has shown itself useful in predicting performance in medicine more generally, and this review raises a strong suggestion that this is an area well worth further study for the benefit of patient care. However, the overwhelming conclusion from this review is how little we actually know about the role of personality and other psychological variables in terms of their effects upon safety at work and, in particular, upon becoming a safe clinician. To remedy this we first need to have well developed outcome measures in terms of safety.

Many people argue against the use of psychometrics for selection into medical school because a broad church is a necessity in an occupation where such varied postgraduate routes can be followed. However, with patient safety being such a critical issue, any studies that explore how we can recognise as early as possible any individual factors that might negatively affect patient care would seem a worthwhile endeavour. In most cases, what matters most here, in terms of working differently, is not so much the ability to select "the right stuff" as it is the early recognition of these differences so that the potential problems they might indicate can be addressed in advance with career counselling, training, and supervision.

\section{Authors' affiliations}

J Firth-Cozens, R Ginsburg, H Cording, The London Deanery, 20 Guilford Street, London WCIN IDZ, UK 


\section{REFERENCES}

1 Department of Health. An organisation with a memory. London: Department of Health, 2000.

2 Sexton JB, Thomas EJ, Helmreich RL. Error, stress, and teamwork in medicine and aviation: cross sectional surveys. BMJ 2000;320:745-9.

3 Firth-Cozens J. Cultures for improving patient safety through learning: the role of teamwork. Qual Saf Health Care 2001;10(Suppl II):iii26-31.

4 Schneider B, Bowen DE. Employee and customer perceptions of service in banks: replication and extension. J Appl Psychol 1985;70:423-33.

5 DiMatteo MR, Sherbourne CD, Hays RD, et al. Physicians' characteristics influence patient's adherence to medical treatment: results from the medical outcomes study. Health Psychol 1993;12(2):93-102.

6 Linn LS, Brook RH, Clark VA, et al. Physician and patient satisfaction as factors related to the organisation of internal medicine group practices. Med Care 1985:23:1171-8

7 Burns R, Sullivan P. Perceptions of danger, risk taking, and outcomes in a remote community. Environment and Behaviour 2000;32(1):32-71.

8 Stewart WH, Roth PL. Risk propensity differences between entrepreneurs and managers: a meta-analytic review. J Appl Psychol 2001;86(1):145-53.

9 Smith SL, Friedland DS. The influence of education and personality on risk propensity in nurse managers. Journal of Nursing Administration 1998;28(12):22-7.

10 Carthey J, De Leval MR, Wright DJ, et al. Behavioural markers of surgical excellence. Safety Science 2003:41:409-25.

11 Norris FH, Smith T, Kaniasty K. Revisiting the experience behavior hypothesis: the effect of Hurricane Hugo on hazard preparedness and other self-protective acts. Basic and Applied Social Psychology 1999;21:19-22.

12 Slovac P. Perception of risk. Science 1987;236:280-5.

13 Zuckerman M, Kuhlman M. Personality and risk-taking: common biosocial factors. J Pers 2000;68:6.

14 Green K, et al. Targeting adolescent risk-taking behaviours: the contributions of egocentrism and sensation seeking. J Adolesc 2000;23(4):439-61.

15 Hovarth P, Zuckerman M. Sensation seeking, risk appraisal and risky behaviour. Personality and Individual Differences 1993;14(1):41-52.

16 Bardo MT, Donohew RL, Harrington NG. Psychobiology of novelty seeking and drug seeking behaviour. Behav Brain Res 1996;77:23-43.

17 Pinkerton SD, Abramson PR. Decision making and personality factors in sexual risk-taking for HIV/AIDS: a theoretical integration. Personality and Individual Differences 1995; 19:713-23.

18 Pierson $\mathbf{A}$, et al. Frontal reactivity and sensation seeking an ERP study in skydivers. Prog NeuroPsychopharmacol Biol Psychiatry 1999;23(3):447-63.

19 Zuckerman M, Eysenck SBG, Eysenck HJ. Sensation seeking in England and America. Journal of Consulting and Clinical Psychology 1978:46:139-49.

20 Rabaud C, Zanea A, Mur JM. Occupational exposure to blood: search for a relation between personality and behaviour. Infect Control Hosp Epidemiol 2000;21(9):564-74.

21 Waldron I, Hickey A, McPherson C, et al. Type A behavior pattern: relationship to variation in blood pressure, parental characteristics and academic and social activities. Journal of Human Stress 1980;6:16-27.

22 Perry AR, Baldwin DA. Further evidence of associations of type A personality scores and driving related attitudes and behaviors. Perception and Motor Skills 2000:91:147-154.

23 Kruger J, Dunning D. Unskilled and unaware of it: how difficulties in recognizing one's own incompetence lead to inflated self-assessments. J Pers Soc Psychol 1999;77(6): 1121-34.

24 Gruppen LD, White C, Fitzgerald JT, et al. Medical students' self-assessments and their allocations of learning time. Acad Med 2000:75:374-9.

25 Firth-Cozens J. Sources of stress in junior doctors and general practitioners. Yorkshire Medicine 1995;10:10-13.

26 Papps BP, O'Carroll RE. Extremes of self-esteem and narcissism and the experience and expression of anger and aggression. Aggressive Behavior $1998 ; 24(6): 421-38$

27 Salmivalli C. Feeling good about oneself, being bad to others? Remarks on self-esteem, hostility and aggressive behaviour. Aggression and Violent Behaviour 2001;6(4):375-93.

28 Schaper M. Small firms and environmental management: predictors of green purchasing in Western Australian pharmacies. International Small Business Journal 2002;20(3):235-52.

29 Ostroff $\mathrm{C}$. The relationship between satisfaction, attitudes, and performance: an organizational level analysis. J Appl Psychol 1992;77(6):963-74.

30 Helmriech RL. Cockpit resource management: exploring the attitudeperformance linkage. Aviat Space Environ Med 1986;57:1 198-200.

31 Helmreich RL, Willhelm JA. Outcomes of crew resource management training The International Journal of Aviation Psychology 1991;1(4):287-300.
32 Firth-Cozens J, Mowbray D. Leadership and the quality of care. Qual Saf Health Care 2001;10(Suppl II):ii3-7.

33 Firth-Cozens J. Interventions to improve physicians' well-being and patient care. Social Science \& Medicine 2001:215-22.

34 Aiken LH, Sloane DM, Sochalski J. Hospital organisation and outcomes. Qual Saf Health Care 1998;7:222-226.

35 Junge $\mathbf{A}$. The influence of psychological factors on sports injuries: review of the literature. Am J Sports Med 2000;28(5):S10-5.

36 Firth-Cozens J. Depression in doctors. In: Katona C, Robertson MM, eds. Depression and physical illness. Wiley: Chichester, 1997:95-111.

37 Winter RO, Binberg B. Working with impaired residents: trials, tribulations and successes. Fam Med 2002;34(3):190-6.

38 Harrison D, Chick J. Trends in alcoholism among male doctors in Scotland. Addiction 1994;89:1613-17.

39 Skipper G. Treating the chemically dependent health professional. J Addict Dis 1997; 16(3):67-73.

40 Flaherty JA, Richman JA. Substance use and addiction among medical students, residents and physicians. Recent Advances in Addictive Disorders 1993;16(1):189-97.

41 Richman JA, Pyskoty CE. Interpersonal versus technological orientations and alcohol abuse in future physicians. British Journal of Addiction 1991;86:1133-8.

42 Hoyle RH. Personality processes and problem behavior. J Pers 2000;68(6):953-66.

43 Forsyth G, Hundelby JD. Personality and situation as determinants of desire to drink in young adults. International Journal of the Addictions 1987;22:653-669.

44 Sicard B. Risk propensity assessment in military specials operations. Mil Med 2001;166(10):871.

45 Firth-Cozens J, Cording H. Do doctors' hours of work and sleep affect the quality of patient care? Qual Saf Health Care 2003;12:(in press).

46 London Deanery of Postgraduate Medical and Dental Education. Recruitment to London/Essex \& Herts/KSS Specialist Registrar Programmes. London: London Deanery of Postgraduate Medical and Dental Education, April 2002:65-68.

47 Reeve PE, Vickers MD, Horton JN. Selecting anaesthetists: the use of psychological tests and structured interviews. Journal of the Royal Society of Medicine 1993;86:400-05.

48 Gilligan JH, Watts C, Welsh FKS, et al. Square pegs in round holes: has psychometric testing a place in choosing a surgical career? A preliminary report of work in progress. Ann R Coll Surg 1999;81:73-9.

49 Hunter JE, Hunter RF. Validity and utility of alternative predictors of job performance. Psychol Bull 1984;96(1):72-98

50 Bobko P, Roth PL, Potosky D. Derivation and implications of a meta-analytic matrix incorporating cognitive ability, alternative predictor and job performance. Personnel Psychology 1999;52:561-89.

51 Ferguson $E$, James $D, O^{\prime}$ Hehir $F$, et al. Pilot study of the roles of personality references and personal statements in relation to performance over five years of a medical degree. BMJ 2003:326:429-32.

52 Gough HG, Bradley P. Performance of residents in anaesthesiology as related to measures of personality and interests. Psychol Rep 1991;68:979-94.

53 Brennan TA, Leape LL, Laird NM, et al. Incidence of adverse events and negligence in hospitalised patients: results of the Harvard Medical Practice Study I. N Engl J Med 1991;324:370-76.

54 Hall JC, Ellis C, Hamdorf J. Surgeons and cognitive processes. Br J Surg 2001;90:10-16.

55 Firth-Cozens J, Lema VC, Firth RA. Speciality choice, stress and personality: their relationship over time. Hosp Med 1999;60:751-5.

56 Stevenson H, Henley S. Job analysis report on the role of the surgeon. Thammes Ditton: Saville and Holdsworth Ltd, 1989.

57 Gibbons RD, Gudas C, Gibbons SW. A study of the relationship between flexibility of closure and surgical skills. J Am Podiatr Med Assoc 1983;3:12-16

58 Deary IJ, Graham KS, Maran AGD. Relationships between surgical ability ratings and spatial abilities and personality. J $R$ Coll Sur of Edinb 1992:37:74-9.

59 Fitzgerald C. Royal College of Surgeons Validation Study. Thames Ditton: Saville and Holdsworth Ltd, 1993.

60 Megargee El. The California psychological inventory handbook. San Francisco, CA: Jossey-Bass, 1986:192.

61 Merrill JM, Camacho Z, Laux LF, et al. Uncertainties and ambiguities: measuring how medical students cope. Med Educ 28:316-22.

62 Firth-Cozens J, Storer D. Making psychiatry attractive. Report to the Leeds Hospitals Trust 2003 